\title{
Triptych: Genesis, Kavana, Sabbath
}

\section{Cover Page Footnote}

This article was made possible by the 2016-2018 Arts and Humanities Research Council (AHRC) Leadership Fellow project 'Judaica: An Embodied Laboratory for Song-Action' [grant reference AH/ N006879/1]. 
The research statements below, by Ben Spatz and Caroline Gatt, accompany the video essays ${ }^{1}$ found at:

\section{https://www.partakejournal.org/triptych}

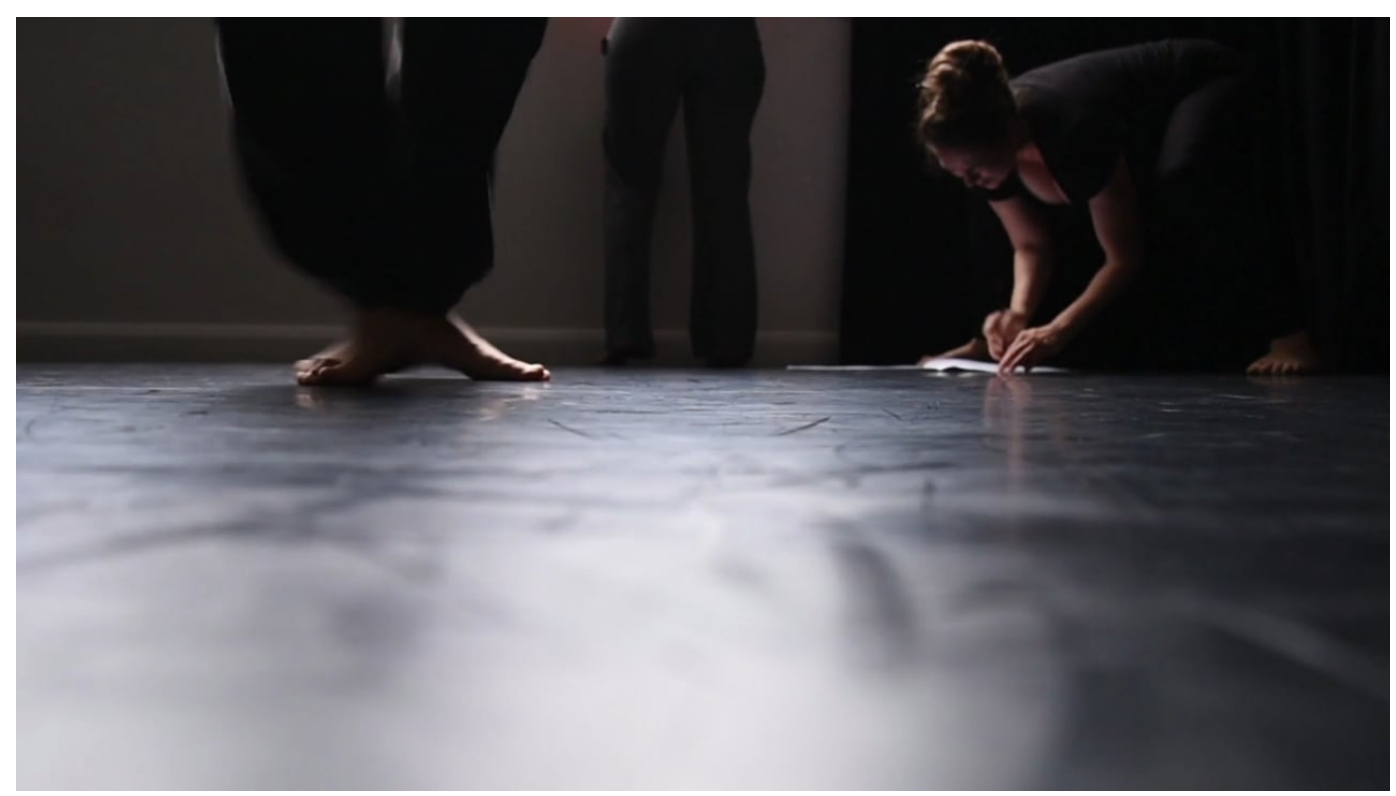

"Genesis" (5:46). Illuminated video essay by Nazlıhan Eda Erçin, Caroline Gatt, Agnieszka Mendel and Ben Spatz. Montage and videography by Ben Spatz. Hebrew alphabet by Bruce Steinberg.

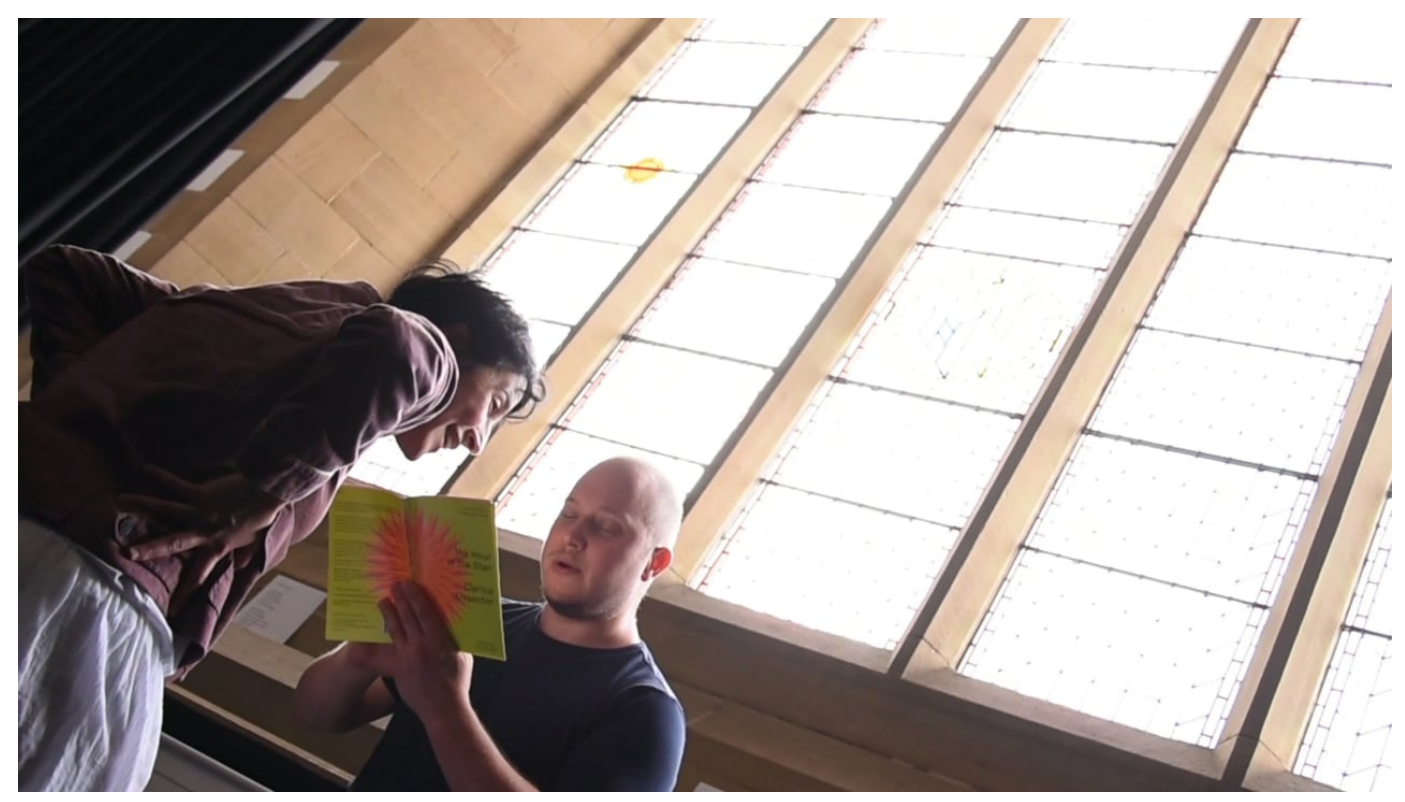

"Kavana" (11:32). Illuminated video essay by Nazlıhan Eda Erçin, Agnieszka Mendel and Ben Spatz, with Garry Cook (external videographer). Videography by Agnieszka Mendel. Montage and annotations by Ben Spatz. 


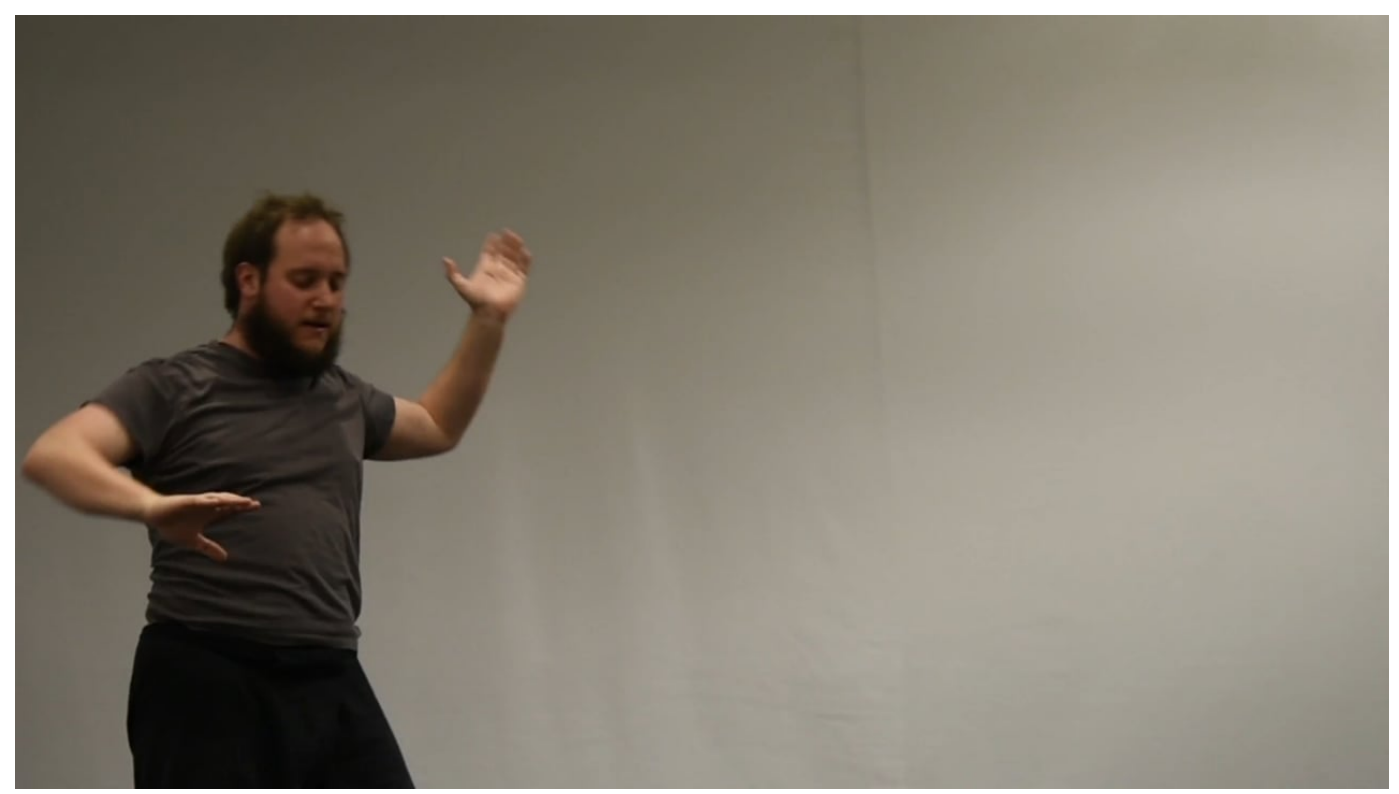

"Sabbath" (7:20). Illuminated video essay by Ben Spatz with Agnieszka Mendel and Nazlıhan Eda Erçin.

\section{Research Statement by Ben Spatz}

These three video essays come out of a multi-year research project that attempts to rethink and redesign the relationship between embodiment and audiovisuality in the context of academic research. ${ }^{2}$ As one anonymous reviewer noted, they gesture towards "a new kind of research artifact, making a space somewhere between standard documentation and contemporary creative product." All three of the video essays comprise footage taken from experimental practice or "laboratory" sessions conducted at the University of Huddersfield in summer 2017. During this period the core research team (Ben Spatz, Nazlıhan Eda Erçin, and Agnieszka Mendel) undertook sustained practice research, working with and through a selection of Jewish music recordings from the Smithsonian Folkways Records archive. ${ }^{3}$ Arising from the project's aim to investigate contemporary identity through songwork, the three videos are linked by the provenance of their titles, each of which names a key concept in Jewish religious thought. However, in no case does the title of the video essay refer to an explicit focus of the documented practice. Rather, the titles were imposed afterwards as part of an editorial process that frames the selected audiovisual material in a particular way, relating it to my own perspective and to the research aims of the project. The relationship between the collaborative dynamics of the documented practice and its subsequent editorial framing raises many questions about the ethics and epistemology of embodied audiovisual research. This research statement does not undertake a full 
exploration of such issues, as doing so would undermine the claim that the triptych stands on its own as a research output. My intention here is only to offer some additional context and methodological background regarding the embodied research process by which these videos were made. ${ }^{4}$

All of the footage used in the video triptych was produced through a collaborative process in which the roles of practitioner, "director," and videographer were shared and circulated amongst members of the research team. ${ }^{5}$ While members of the team share a background in actor-led, post-Grotowskian experimental performance practices - and, within the core team, also an explicit commitment to working with a particular archive of songs — we never developed anything like a set performance structure, score, or composition. Because the roles of director and practitioner were constantly shifting, the structure of practice likewise shifted from day to day. And because one of us always had the role of videographer, this process generated a large amount of audiovisual material tracing a wide variety of moments. The process was conceived of as "blue skies" research (without any immediate application), where instead of testing a propositional thesis we would be exploring a specified epistemic space defined by the intersection of our own knowledge and identities with the selected material - in this case, songs. In the context of such an open-ended process, the question of the meaning and "aboutness" of any given session or moment only comes sharply into focus when one begins to think about framing the audiovisual material discursively and making it available to others. Regardless of whether a given moment was ostensibly "about" anything at the time, the aboutness of each moment of practice may be experienced and recalled differently by everyone involved. While this is true of any collaboration, the extensive use of audiovisual recording in our process, combined with the commitment to produce videographic publications out of the lab sessions, concretizes the question of aboutness as a practical and creative problem for the video editor.

There are then two distinct moments and modes of collaboration in this process: In the first, real-time embodied interaction generates "raw" audiovisual footage that could not exist without the presence and engagement of everyone involved. In the second, one or more editors select and shape some of that material for publication, a process that is more like collaborative writing (a back-and-forth mediated by a technological object) than performance improvisation. Because our process relied on the shifting of roles and not the composition of a repeatable score, there never was any performance structure or practice session called "Genesis" or "Kavana" or "Sabbath." There is therefore no "performance documentation" here, in the conventional sense of 
a secondary recording that (always inadequately) documents a performance event understood as the primary site of meaning. Instead, a handful of audiovisual moments have been selected from amongst hundreds of hours of footage, and certain possible meanings have been drawn out from them via editorial choices. The role of the editor here is powerful. In the project's first publication, the online Songwork Catalogue, the power of the editorial role was strictly limited. ${ }^{6}$ Each contributor, including a series of "guests" who visited the laboratory for a few days or a week, took turns selecting short fragments of material and giving them titles. No further editing was allowed and both the selection (in-point / out-point) and the title had to be agreed by consensus among everyone involved. In this way we were able to produce a large videographic "catalogue" that was effectively co-authored at the editorial as well as the embodied stage.

Having established this as a possible mode of collaborative publication, we began to explore the construction of more complex video essays involving greater individual authorship in the editorial role. Each of us began to edit our own video essay projects, selecting raw material and making editorial choices that suggest particular kinds of meaning. With this shift came new questions and conversations about collaboration and consent. At present, all three of us continue to work on the creation of video essays using material generated during the lab period. ${ }^{7}$ However, the economic structure of the project - which was designed and locked into place before the full ethical and epistemological complexity of the approach was understood - puts me as project leader in a position of privilege when it comes to this later phase of production, as I am the only member of the team who was funded to continue the research beyond the laboratory phase. The videos in this triptych are "mine" in the sense that they represent my selection and framing of collaboratively produced audiovisual material. However, the actual relationship between the two moments of collaboration is complex. The power of the editor is not quantitatively greater than that of the lab practice in any straightforward way. Rather, specific editorial techniques and strategies intervene in the unedited material in qualitatively different ways. Distinct elements of montage such as titles, annotations, voiceovers, image overlays, cuts, etc. - implement distinct epistemic relationships to the audiovisual material. These differences pertain to any video editing process, but in this case I am working not with dramatically scripted material, as in narrative filmmaking, or even with "found" material, as in some video art, but with collaboratively generated research material in which my own participation was fully embedded and embodied. In editing these three videos and placing them 
alongside each other, I am working through my own positionality in relation to academic research between the United States and the United Kingdom; embodied practice integrating textuality, physicality, and musicality; and Jewishness as a complex and contested cultural-religious-ethnic-racial identification.

As a whole, the triptych aims to demonstrate that embodied audiovisual research can produce meaning that goes beyond a literal illustration of its own method to engage with philosophical and religious concepts. Other possible titles — such as "Rhythm" instead of "Genesis", "Chanting" instead of "Kavana", or "Resting" instead of "Sabbath" - would point the viewer toward concepts that more commonly structure ensemble and improvisational practice in Performance as Research contexts. (Many of the titles in the Songwork Catalogue are more technical in this sense.) Instead I have chosen titles that bring the audiovisual material into contact with Jewish religious concepts, a tactic that I hope both defamiliarizes the documented practice and strategically appropriates these theological concepts. Beyond that, each video employs different editorial techniques and deals with questions of meaning and aboutness in a different way. For example, "Genesis" is the only video in the triptych where I do not visually appear. Using footage from the fourth day of a visit by anthropologist and performer Caroline Gatt to our lab, I attempt to draw out the understated complexity of the documented practice by juxtaposing it with integrated montage elements that point to the theme of origins. My sudden reading of a fragment of Genesis from the Hebrew Bible (Tanakh) becomes the explicit topic of the video. Against the grain of this potentially overbearing classicism, a single superimposed quotation from philosopher Giorgio Agamben points to the problematic relationship between ontological and political power in the constitution of sovereignty: "[C]onstituting power, when conceived in all its radicality, ceases to be a strictly political concept and necessarily presents itself as a category of ontology." ${ }^{8}$ While I could elaborate here on what I understand to be the relationship between the audiovisual material, the framing title, and the Agamben quote - as well as between the knowledge that structures the documented practice and that which orients my editorial choices - I maintain that these relations are best articulated in the video montage itself.

A very different relationship between textuality and audiovisuality is found in "Kavana," where a series of dense quotations precede an extended fragment of dynamic vocal and physical practice. I doubt that any viewer will comprehend and retain awareness of the five preliminary texts throughout the video and I therefore rely on the possibility of repeated viewings to draw out both the internal trajectory of the texts and 
their relationship to the audiovisual material. As in "Genesis," the sparsity of textuality in the video is intended to overturn the conventional academic hierarchy according to which the audiovisual fits within a larger textual scheme. In both of these video essays, textual elements (apart from the title) are conceived as annotations and supplements to help unlock audiovisual perception and draw out the generative complexity of practice. In this regard, it is important that both audiovisual sequences are uncut. Although the editorial interventions are more intensive here than in the Songwork Catalogue, the same limitation has been applied when it comes to the selection of material: I have chosen an in-point and an out-point and have made no further cuts or montage. This accords a certain wholeness and transparency to the moment of practice. While the editing certainly frames their meaning, those minutes independently took place as shown. A viewer might wonder what happened before and after that moment, but they can rely upon each fragment's documentary veracity: We did use our bodies and voices in that way. The fact that "Kavana" shows the first moment in which I linked a learned melody with a written text in precisely this way means that the video captures not just a moment of research in general but a moment of actual discovery. But here again, I do not think this background knowledge is essential to what the video essay tries to communicate about and through the concept of spiritual intention or "kavana."

In contrast, the third video, "Sabbath," makes multiple editorial cuts and imposes a voiceover on the documented practice. I am certain that I felt free to make these greater editorial impositions because the unedited video material documents almost exclusively my own solo practice and audiovisual body. The first-person voiceover, which speaks simply and directly about personal experiences and working principles, makes it likely the most accessible of the three video essays. Here for the first time a traditional "argument" is provided in spoken essay form: a definition of sabbath much broader than the religious Sabbath, which draws on Jewish tradition to explore strategies for structuring activity and rest in and beyond studio practice. With this video we arrive to what is presumably more familiar audiovisual territory, where the image apparently serves to illustrate a spoken essay. Perhaps this video could serve as a useful entry point to the triptych? By placing it last, I instead suggest that a return to the assumed primacy of text can be a welcome resting point after more intensive journeys through audiovisual meaning.

As a triptych, the three videos propose a range of approaches exploring the imbrication of textuality and audiovisuality in what I am calling dense or "illuminated" video. Density here refers to the layers of citationality that characterize academic 
writing, while illumination is a reference to the illuminated manuscripts of medieval Europe, here inverted with textual "illuminations" supplementing a primarily audiovisual work. ${ }^{9}$ In the context of the Judaica project, the layering of text on top of image also recalls the density of Talmudic commentary, which has been called the first form of hypertext. The three essays treat three important concepts in Jewish religious practice, but they do not do so by enlisting the audiovisual as an illustration of textual thought. Rather they propose that, in order to fully enter the audiovisual way of thinking, we must change the way we perceive the relationship between voice, body, movement, and text. The implicit argument made by the triptych is that audiovisual documents - even or especially when they show uncut moments of experimental practice - robustly articulate knowledge insofar as they can circulate as relatively stable documents forming a new kind of archive. This knowledge inheres in the moving, sounding, and knowing bodies of the practitioners and in the particular (auditory and visual) ways those bodies are inscribed by the video medium. Textuality may be necessary to render that knowledge accessible in an interdisciplinary context, but it can only do so by working to highlight the irreducibility of what are here presented as fundamentally audiovisual ways of knowing.

\section{Research Statement by Caroline Gatt}

I began my training in research theatre in parallel with carrying out my undergraduate studies in social anthropology. The two experiences were to remain equally important in my subsequent studies and work. I have found that theatre and anthropology are cosmoi, multiple moving shifting universes, which can easily converge at some points due to certain inherent resonances. ${ }^{10}$ Within my own sphere of experience, those cosmoi converged to form multiple aspects of myself. How, I wondered, could this be more than an individual formation or coincidence?

In recent years, therefore, my investigations led me to explore the possible mutualities between the ways of knowing of theatre and of anthropology on a disciplinary scale, in particular by exploring some of the key daily practices of both. ${ }^{11}$ Mary Carruthers' studies of monastic Medieval writing, reading and memory practices in Western Europe have been particularly valuable in this. ${ }^{12}$ What the comparison between Medieval and contemporary reading and analytical practices suggests is that the theories of knowledge embedded in these practices shape not only "what is known, but what is knowable."13 The daily practices of anthropologists as much as those of 
research theatre makers grow what I am referring to as "knowing bodies" that can attend and perceive in particular ways.

What is presented in the video essay "Genesis" is a fragment of a week-long exchange in June 2017 between myself and Ben Spatz, N. Eda Erçin and Agnieszka Mendel. During this meeting I offered the approaches I had been developing in relation to the questions I mentioned above. Ben, Eda and Agnieszka offered the approaches and questions they had been devising and exploring through Ben's AHRC Leadership Fellow project "Judaica: An Embodied Laboratory for Songwork." The footage in "Genesis" comes from the fourth day of my visit to Huddersfield. Earlier in the week I had shared my research by leading a session for which I had asked Ben, Eda and Agnieska to read two anthropology articles beforehand. Then I brought photocopies of these readings, A3 size unlined drawing books with plain soft matt black paper covers, and an array of charcoal, chalk, pens, markers, pencils, rulers, erasers and pencil sharpeners to the studio. Drawing on my own studio work with books, writing and academic language as part of experimental performance research that I carried out between 2013 and 2018 with the support of the ERC-funded project Knowing from the Inside, I invited the participants - Ben, Eda and Agnieska - to explore the readings in the studio through the exploratory performance practices they used on a daily basis. What I asked of them was intentionally vague. It was up to them to explore the anthropological writings as they wished, only with the guiding note to give value to the studio ways of searching and exploring they were expert at.

By the fourth day, which as I mentioned is partly included in the video essay, our joint work already began to cross-fertilize. What I see in the video essay is Eda, Agnieska and myself merging our explorations, including the songs they had worked with previously and also the paper, pen and the memory of the texts we had all read. In the meantime, Ben participated in the role of documenter/performer. Ben's presence is palpably informed by the initial meeting between our respective research interests. Ben engages with their work on filming with the sensitivity of a participating performer and reads from the Tanakh, which they tell me they would not have considered bringing into the studio before participating in the session I had led.

Working with and through illuminated video essays, I have found, transforms my perceptions of research activities and relationships. As with the socially and historically contingent involvement of books in academia, the particular artifacts enlisted and made through a practice participate in the constitution of an ecology of practice/knowledge. ${ }^{14}$ In this case the illuminated video essay offers another small step 
in the growth of an emergent ecology of practice/knowledge in which performative epistemologies are finally valorized.

${ }^{1}$ Videos are also accessible from the authors' research website at: http://urbanresearchtheater.com/2017/08/02/triptych-genesis-kavana-sabbath/

2 "Judaica: An Embodied Laboratory for Songwork" (2016-2018) was supported by the UK Arts and Humanities Research Council under the Leadership Fellows scheme www.ahrc.ac.uk. The core of the project was six months of full-time embodied research with three skilled practitioners in a studio laboratory, including structured experimental practice and a series of public presentations. For more information about the project and its outcomes, please visit www.urbanresearchtheater.com.

${ }^{3}$ The initial selection included eighteen albums marked in the Smithsonian Folkways digital archive as "Judaica," which range widely in terms of cultural, geographic, historical, religious, and linguistic context. For more on the choice of recordings and the implications of working with them, see Ben Spatz, "Molecular Identities: Digital Archives and Decolonial Judaism in a Laboratory of Song," Performance Research 24, no. 2 (forthcoming); and Nazlıhan Eda Erçin, "From-ness: The Identity of the Practitioner in the Laboratory," Theatre, Dance and Performance Training 3, no. 2 (2018): 195-202.

${ }^{4}$ The idea of embodied research is proposed in Ben Spatz, What a Body Can Do: Technique as Knowledge, Practice as Research (New York and London: Routledge, 2015) and further developed in "Tinkering, Tuning, Tracking: Embodiment as First Affordance," Performance Philosophy 2, no. 2: 257-271; "Colors Like Knives: Embodied Research and Phenomenotechnique in Rite of the Butcher," Contemporary Theatre Review 27, no. 2: 195-215; and "Mad Lab - or Why We Can't Do Practice as Research," in Performance as Research: Knowledge, Methods, Impact, eds. Annette Arlander, Bruce Barton, Melanie Dreyer-Lude, and Ben Spatz (New York and London: Routledge, 2018). The ontoepistemological implications of foregrounding video as an archival medium are explored in "The Video Way of Thinking," South African Theatre Journal 31, no. 1 (2018): 146-154.

5 The term "director" is in quotation marks because it refers to one who may offer directions to the practitioner(s) in the moment but who does not retain any futureoriented compositional power: a "director of practice" and not director of the overall process. The embodied audiovisual research method developed during the Judaica project is described in Ben Spatz Making a Laboratory: Dynamic Configurations with Transversal Video (New York: Punctum Books, forthcoming).

${ }^{6}$ Ben Spatz, Nazlıhan Eda Erçin, and Agnieszka Mendel, Songwork Catalogue (Urban Research Theater 2017), available online: www.urbanresearchtheater.com/songwork.

7 This triptych is the second such video essay to be formally published in a peerreviewed online journal. The first is Ben Spatz with Nazlıhan Eda Erçin, Agnieszka Mendel, and Elaine Spatz-Rabinowitz, "Diaspora (An Illuminated Video Essay)," Global Performance Studies 2, no. 1 (2018), available online: gps.psiweb.org/issue-2-1/diaspora. 
${ }^{8}$ Giorgio Agamben, Homo Sacer: Sovereign Power and Bare Life (Stanford University Press, 1998): 44.

${ }^{9}$ I proposed the idea of "dense" video in Ben Spatz, "What Do We Document? Dense Video and the Epistemology of Practice," in Documenting Performance: The Context and Processes of Digital Curation and Archiving, ed. Toni Sant (Bloomsbury Methuen Drama, 2017): 243-253. The idea of "illuminated" video arose during the Judaica project lab and was inspired by Caroline Gatt's work with books, which she describes below.

${ }^{10}$ Caroline Gatt, "Converging Cosmoi: The possibilities inherent in an interdisciplinary contact between theatre and anthropology," paper presented at the Summer University of Performing Arts, Malta, August 2006.

11 This research was part of my project "Crafting Anthropology Otherwise", a subproject within "Knowing from the Inside" (PI Tim Ingold, 2013 - 2018), which was supported by the European Research Council. I would like to thank Tim Ingold for giving me carte blanche to develop my research; Gey Pin Ang, who was my close collaborator for the whole duration of the project; Valeria Lembo, my research assistant and collaborator during the project; and all the participants in the various experimental field workshops I carried out in developing the methods for my research; as well as Ben Spatz, for inviting me, the first of a series of guests, into the precious studio work they were developing in Huddersfield as part of the Judaica project, and Nazlıhan Eda Erçin and Agnieszka Mendel, for welcoming me so open-heartedly and for all the formative exchanges I had with the three of them.

${ }^{12}$ See Mary Carruthers, The Book of Memory: A Study of Memory in Medieval Culture (Cambridge University Press, 2008 [1990]) and Mary Carruthers, The Craft of Thought: Meditation, Rhetoric, and the Making of Images, 400 - 1200 (Cambridge University Press, 2008 [1998]).

${ }^{13}$ Greg Downey, "Seeing With a 'Sideways Glance': Visuomotor 'Knowing' and the Plasticity of Perception," in Ways of Knowing: New Approaches in the Anthropology of Knowledge and Learning, ed. Mark Harris (New York and Oxford: Berghahn Books, 2007): 222-241.

${ }^{14}$ Caroline Gatt, "The Liveliness of Books," in The Voices of the Pages, ed. Caroline Gatt (Aberdeen: University of Aberdeen, 2017). 